\title{
ACUTE LEFT VENTRICULAR THROMBUS POST ACUTE MYOCARDIAL INFARCTION NEEDING CORONARY REVASCULARISATION
}

\author{
Satish Govindaiah¹, Vivekanand Siddaiah², Manish Pangi ${ }^{3}$, Sudheer Lakshman ${ }^{4}$
}

${ }_{1}^{1}$ Associate Professor, Department of Cardiac Surgery, Sri Jayadeva Institute of Cardiovascular Sciences and Research, Bangalore, Karnataka, India.

${ }^{2}$ Associate Professor, Department of Cardiac Surgery, Sri Jayadeva Institute of Cardiovascular Sciences and Research, Bangalore, Karnataka, India.

${ }^{3}$ Associate Professor, Department of Cardiac Surgery, Sri Jayadeva Institute of Cardiovascular Sciences and Research, Bangalore, Karnataka, India.

${ }^{4}$ Postgraduate Student, Department of Cardiac Surgery, Sri Jayadeva Institute of Cardiovascular Sciences and Research, Bangalore, Karnataka, India.

HOW TO CITE THIS ARTICLE: Govindaiah S, Siddaiah V, Pangi M, et al. Acute left ventricular thrombus post acute myocardial infarction needing coronary revascularisation. J. Evolution Med. Dent. Sci. 2018;7(28):3259-3261, DOI: $10.14260 /$ jemds/2018/733

\section{PRESENTATION OF CASES}

Left ventricular thrombus is a common complication of acute myocardial infarction, especially of the anterior and apical walls, appearing in 33 to $68 \%$ of autopsies or 20 to $40 \%$ of two-dimensional echocardiographic studies. ${ }^{1-4}$ Left ventricular (LV) thrombus is a life-threatening complication of severe left ventricular dysfunction. The following cases illustrate our experience in treating patients with acute left ventricular thrombi.

\section{Case 1}

A 64-year-old man, known case of diabetes mellitus and hypertension presented with angina since 20 days and was diagnosed to have anterior wall MI, moderate LV dysfunction, EF of $35 \%$ with akinetic anterolateral and inferior segments and also had a large clot at LV apex which was mobile, pedunculated measuring $3.6 \times 2.1 \mathrm{~cm}$.

Coronary angiogram showed TVD, requiring surgery only. $\mathrm{He}$ was started on antiplatelets and heparin. He was haemodynamically stable with pain relieved by medication. Serial echocardiograms showed regression in the size of the clot and hence trial of anti-coagulation with injection Heparin 5000 IU given intravenously q.i.d. was continued.

Repeat echo showed complete dissolution of clot after 15 days. He was then taken up for CABG done using off pump technique with grafts to LAD and RCA. Intraoperative TEE showed no e/o clot. Postoperatively, he recovered smoothly without any embolic events. Discharged after 7 days with acitrom and antiplatelets. On follow-up echo after 3 months, patient was symptom free with good LV function and no e/o clot.

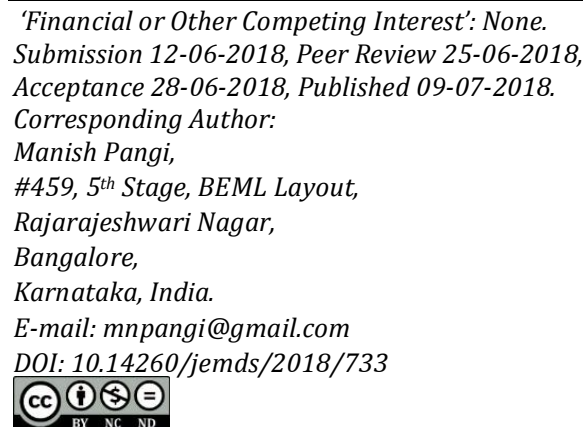

During a 6-month period, 3 patients with a mobile, pedunculated left ventricular thrombus were encountered in our unit. All 3 patients had a recent history of myocardial infarction. The thrombus was removed during the acute phase of myocardial infarction in 1 patient and concomitant coronary artery bypass grafting was performed. The other two patients were stable, hence put on a trial anticoagulation and after dissolution of the clot were operated with off pump technique. There were no deaths and none of the patients had clinical or echocardiographic evidence of recurrent thrombi or emboli at follow-up 3 months later. These results indicate that in stable patients, a trial of anticoagulation can be done successfully.

\section{Case 2}

A 54-year-old man, known diabetic, hypertensive, old AWMI s/p PTCA to LAD, presented with chest pain on exertion and was diagnosed to have IWMI with large mobile, pedunculated LV apical clot $3.4 \times 1.9 \mathrm{~cm}$ with akinetic anteroseptal and apical segments.

Coronary angiogram showed DVD with in-stent restenosis. He was started on Inj. Heparin 5000 IU IV q.i.d. Patient continued to have ongoing chest pain; hence, he was taken for emergency coronary revascularisation. CABG was done with grafts to LAD and RCA and clot was completely evacuated during the same procedure. Intraoperative TEE was done to confirm clot evacuation.

Post-operatively, he improved well without any embolic events and was discharged in stable condition. He was prescribed Acitrom to maintain INR of 1.5 to 2. On follow-up echo after 3 months, patient was symptom free with good LV function and no e/o clot.

\section{Case 3}

A 56-year-old male, known diabetic and hypertensive presented with atypical chest pain since 15 days diagnosed to have NSTEMI, unstable angina with LV segmental hypokinesia of anterolateral, basal infero-posterior segments and had a mobile, pedunculated LV clot $3.3 \times 1.9 \mathrm{~cm}$ situated at the inferior wall. It was found to be closely adherent to the papillary muscle bundles. Coronary angiogram revealed LMCA and TVD, started on antiplatelets and anticoagulation with Inj. Heparin.

Serial 2D echocardiogram showed regression in size of $\mathrm{LV}$ clot and TEE during surgery showed no e/o clot. He 
underwent off pump coronary revascularisation with grafts to LAD and PDA.

Post-operatively, he improved well without any embolic events and follow-up echo after 3 months showed no e/o clot.

\section{DIFFERENTIAL DIAGNOSIS}

Similar presentation might have been seen in intracardiac tumours, the commonest of which would have been a myxoma.

\section{PATHOLOGICAL DISCUSSION}

Histopathological examination of the specimen obtained from the first cases revealed it to be a thrombus, confirming our clinical diagnosis.

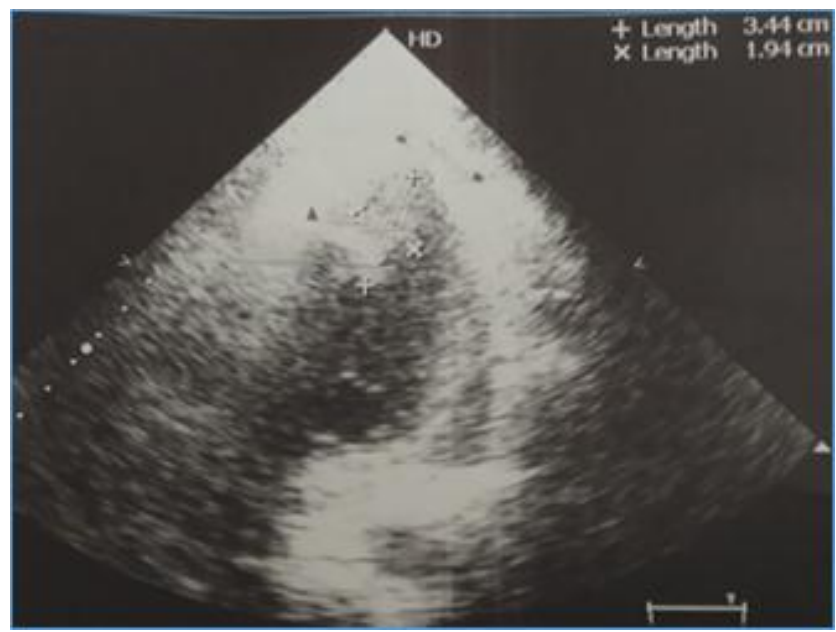

Figure 1. Echocardiography showing Mobile Pedunculated Clot at LV apex

\section{DISCUSSION ON MANAGEMENT}

The possible treatment options include anticoagulation, thrombolysis and surgical thrombectomy. ${ }^{1-2}$ Small immobile thrombi can be safely managed with anticoagulation; however, treatment for large mobile thrombi is often problematic. LV thrombus is usually associated with poor LV function. ${ }^{3}$ Therefore, surgical approaches such as left ventriculotomy, which potentially cause further deterioration of LV function should be avoided if possible. 5

Mobile, pedunculated thrombi are rare in comparison to mural thrombi, but carry a significantly higher risk of embolisation.6-9 Although, under anticoagulant treatment some of the left ventricular thrombi may resolve ${ }^{4}$ and the rate of systemic emboli may be reduced significantly. ${ }^{2}$ Recurrent embolisation under anticoagulant treatment has been reported.6,7 Moreover, the outcome of patients with recurrent emboli due to mobile, pedunculated thrombi who were not operated on was generally very poor 6,7 as compared with the limited experience with those who underwent an operation.

Left ventricular thrombus is a common complication following myocardial infarction with or without left ventricular aneurysm or cardiomyopathy. On autopsy studies, left ventricular thrombus was found in 33 to $68 \%$ of patients following myocardial infarction. $1,2 \mathrm{~A}$ rare type of left ventricular thrombus is a pedunculated thrombus, that is connected to the ventricular wall or septum by a narrow stalk and that moves throughout the cardiac cycle. Such thrombi have an especially high tendency of embolisation despite adequate anticoagulant treatment. However, operating on this sub-group of patients with friable myocardium, systemic complications and doing a ventriculotomy for clot evacuation is especially hazardous. It can result in increased bleeding, arrhythmias and poor outcome.

Based on our results, despite a limited group of patients and on the few reported cases in the literature,, 79 we believe that a trial of anticoagulation can be done in stable patients while serially monitoring them using echocardiography. ${ }^{10.11}$ We also believe that the routine and repeated use of two dimensional echocardiography ${ }^{12}$ in patients after acute myocardial infarction will detect the pedunculated thrombi. Any reduction in size of clot should result in continuation of this trial, as the ability to avoid thrombectomy in such sick patients can obviously result in better outcomes as was seen in our patient group.5,10,11 Additionally, the surgery can be done using off pump technique as was done in our group, which can avoid pump related complications in these sick patients.

Hence, we believe that in patients with LV clot post-acute myocardial infarction with stable haemodynamics, needing surgical revascularisation, a trial of conservative management with anticoagulation can be done. In case of ongoing symptoms or failure of size reduction, patient can be taken for early revascularisation with clot evacuation.

\section{FINAL DIAGNOSIS}

LV clot, post-acute myocardial infarction.

\section{REFERENCES}

[1] Jordan RA, Miller RD, Edwards JE, et al. Thromboembolism in acute and healed myocardial infarction. I. Intracardiac mural thrombosis. Circulation 1952;6(1):1-6.

[2] Visser CA, Kan G, Lie KI, et al. Left ventricular thrombus following acute myocardial infarction: a prospective serial echocardiographic study of 96 patients. Eur Heart J 1983;4(5):333-7.

[3] Asinger RW, Mikell FI, Elsperger J, et al. Incidence of left-ventricular thrombosis after acute transmural myocardial infarction. Serial evaluation by twodimensional echocardiography. $N$ Engl J Med 1981;305(6):297-302.

[4] Spirito P, Bellotti P, Chiarella F, et al. Prognostic significance and natural history of left ventricular thrombi in patients with acute anterior myocardial infarction: a two dimensional echocardiographic study. Circulation 1985;72(4):774-80.

[5] DiBernardo LR, Kirshbom PM, Skaryak LA, et al. Acute functional consequences of left ventriculotomy. Ann Thorac Surg 1998;66(1):159-65.

[6] Visser CA, Kan G, Meltzer RS, et al. Long-term followup of left ventricular thrombus after acute myocardial infarction: a two dimensional echocardiographic study in 96 patients. Chest 1984;86(4):532-6.

[7] Chesebro JH, Ezekowitz M, Badimon L, et al. Intracardiac thrombi and systemic thromboembolism: detection, incidence and treatment. Annu Rev Med 1985;36:579-605. 
[8] Hangland JM, Asinger RW, Mikell FL, et al. Embolic potential of left ventricular thrombi detected by two dimensional echocardiography. Circulation 1984;70(4):588-98.

[9] Meltzer RS, Visser CA, Kan G, et al. Two-dimensional echocardiographic appearance of left ventricular thrombi with systemic emboli after myocardial infarction. Am J Cardiol 1984;53(11):1511-3.

[10] Lew AS, Federman J, Harper RW, et al. Operative removal of mobile pedunculated left ventricular thrombus detected by two dimensional echocardiography. The Am J Cardiol 1983;52(8):11489.
[11] Lee JM, Park JJ, Jung HW, et al. Left ventricular thrombus and subsequent thromboembolism, comparison of anticoagulation, surgical removal and antiplatelet agents. J Atheroscler Thromb 2013;20(1):73-93.

[12] Stratton JR, Lighty GW Jr, Pearlman AS, et al. Detection of left ventricular thrombus by two-dimensional echocardiography: sensitivity, specificity and causes of uncertainty. Circulation 1982;66(1):156-66. 